04.1;06.4; 12.1

\title{
Получение керамики на основе карбида кремния из золошлаковых отходов
}

\author{
(C) А.Я. Пак, В.Е. Губин, Г.Я. Мамонтов
}

Национальный исследовательский Томский политехнический университет, Томск, Россия

E-mail: ayapak@tpu.ru

Поступило в Редакцию 23 марта 2020 г.

В окончательной редакции 13 апреля 2020г.

Принято к публикации 13 апреля 2020 г.

Показана возможность создания объемных образцов твердой керамики на основе карбида кремния, полученного из золошлаковых отходов. Процесс реализован в три этапа: исходные золошлаковые отходы обрабатывались углеродной плазмой дугового разряда постоянного тока при нормальных атмосферных условиях безвакуумным методом, затем полученный порошковый материал очищался от несвязанного углерода в атмосферной печи, на финальной стадии порошковый продукт спекался методом искрового плазменного спекания. Согласно данным аналитических методик, в результате получена керамика на основе карбида кремния с плотностью $3.05 \mathrm{~g} / \mathrm{cm}^{3}$ и твердостью до $19.9 \mathrm{GPa}$.

Ключевые слова: карбид кремния, электродуговой синтез, безвакуумный метод, искровое плазменное спекание.

DOI: 10.21883/PJTF.2020.14.49661.18302

Утилизация золошлаковых отходов (золы), образующихся при сгорании природного угля, является одной из основных экологических проблем энергетической отрасли [1], которой уделяется значительное внимание ученых во всем мире [1,2]. Ввиду широкого диапазона достигаемых температур многообещающими выглядят плазменные методы переработки отходов, научнотехническая база которых еще не достигла достаточного уровня для повсеместного применения [3]. Основными задачами развития плазменных методов переработки сложноутилизируемых отходов можно считать необходимость упрошения плазменных реакторов, повышения их энергетической эффективности, поиск методов получения востребованных материалов в результате переработки $[4,5]$. Возможными решениями могут быть реализация процесса переработки при атмосферном давлении [6], а также получение в результате переработки твердой (обычно оксидной) керамики на основе кремния и алюминия $[7,8]$. В настоящей работе представлены результаты экспериментальных исследований, посвященные получению керамики на основе карбида кремния из золы природного угля, обработанной плазмой дугового разряда постоянного тока, инициированного в открытой воздушной среде. Упоминаний о возможной реализации такого метода переработки золошлаковых отходов авторами не обнаружено.

В ходе подготовки серии экспериментов зола природного угля размалывалась в шаровой мельнице в течение $30 \mathrm{~min}$. Полученный порошок загружался в полый графитовый катод в количестве $0.5 \mathrm{~g}$ и обрабатывался плазмой дугового разряда постоянного тока безвакуумным методом [9]. Метод основан на эффекте экранирования реакционного объема от кислорода воздуха при интенсивной генерации оксидов и диоксидов углерода в процессе горения дугового разряда постоянного тока при нормальных атмосферных условиях [9-11]. Такой подход существенно снижает количество потребляемой реактором энергии, упрощает его конструкцию, увеличивает производительность [9-11]. В ходе экспериментов поддерживался ток разрядного контура в диапазоне 190-200 А в течение $30 \mathrm{~s}$, что соответствует количеству подведенной энергии до $\sim 158 \mathrm{~kJ}$ при средней мощности разряда $\sim 5.1 \mathrm{~kW}$. В серии экспериментов накоплено $4.1 \mathrm{~g}$ порошкового продукта, который очищался от графитовых примесей (являющихся побочным продуктом работы разрядного контура дугового реактора с графитовыми электродами $[9,11])$ путем сжигания порошка в атмосферной печи (ЭКСП 10, $2.8 \mathrm{~kW}$ ) при температуре $750^{\circ} \mathrm{C}$ в течение $2 \mathrm{~h}$. Температура отжига предварительно определялась по данным термического анализа (Netzsch STA 449 C Jupiter). Очищенный порошок консолидировался методом искрового плазменного спекания (SPS, 10-4 Advanced Technologies) при температуре $1800^{\circ} \mathrm{C}$, давлении $60 \mathrm{MPa}$ в течение $5 \mathrm{~min}$. В результате был получен керамический образец с плотностью $3.05 \mathrm{~g} / \mathrm{cm}^{3}$. Материалы анализировались методами рентгеновской дифрактометрии (Shimadzu XRD $7000 \mathrm{~s}, 1.5406 \AA$ ), растровой электронной микроскопии с энергодисперсионным анализом (Tescan Vega 3 SBU, Oxford X-Max-50, Hitachi ТМ3000). Твердость керамического образца измерялась на микротвердомере ПМТ3 (при массе нагружения $200 \mathrm{~g}$ по методу Виккерса).

Согласно данным рентгеновской дифрактометрии, в исходной золе (рис. 1, кривая 1) идентифицируется множество кристаллических фаз, основными из которых следует считать оксидные фазы на основе кремния и алюминия (кварц $\mathrm{SiO}_{2}$, корунд $\mathrm{Al}_{2} \mathrm{O}_{3}$, муллит $\mathrm{Al}_{x} \mathrm{Si}_{y} \mathrm{O}_{z}$ ). Кроме максимумов, соответствующих основным фазам, 


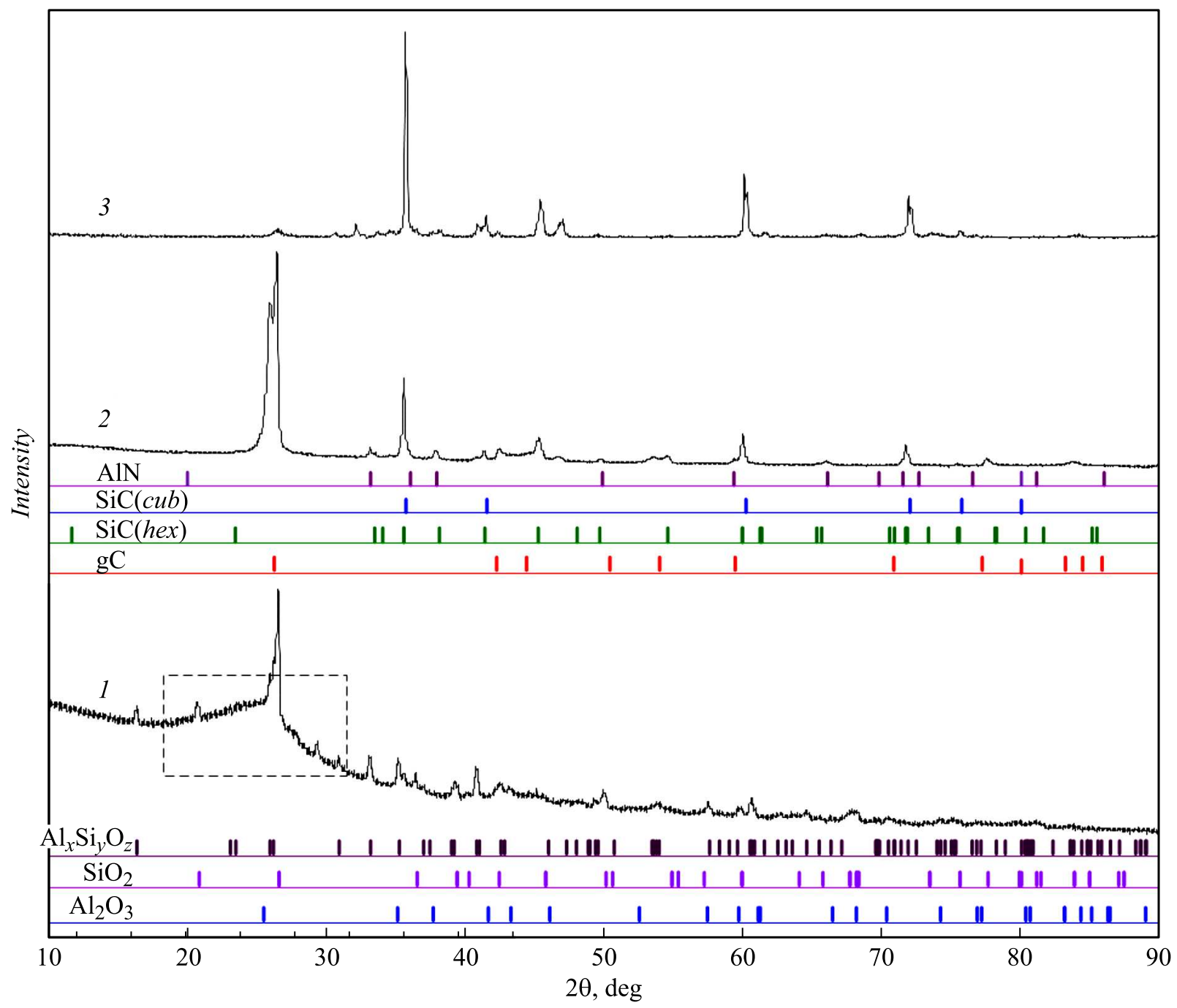

Рис. 1. Типичные рентгеновские дифрактограммы исходного золошлакового материала (1), типичного продукта электродугового синтеза до очистки от графита в атмосферной печи (2), очищенного и затем спеченного методом искрового плазменного спекания продукта синтеза (3).

идентифицируется множество малоинтенсивных следов, которые могут соответствовать оксидам титана, железа и других распространенных химических элементов, а также видно аморфное гало на интервале $\sim 20-30 \mathrm{deg}$. Эти данные соответствуют известным сведениям о типичном фазовом составе золы [2,8]. Дифрактограмма золы, обработанной в плазме дугового разряда постоянного тока (рис. 1, кривая 2), значительно отличается от исходной. Однозначно идентифицируется фаза графита (gC), видны дифракционные максимумы, соответствующие структурам кубической и гексагональной фаз карбида кремния $\mathrm{SiC}$, гексагональной фазы нитрида алюминия AlN. Фазы карбида кремния образуются в результате воздействия на оксид кремния высоких температур в присутствии углерода (согласно известной диаграмме состояний кремний-углерод). Формирование гексагональной фазы нитрида алюминия в плазме дугового разряда постоянного тока в присутствии алюминия и га- зообразного азота считается возможным явлением [12]. Продукт с аналогичным фазовым составом был получен ранее авторами работы [13], в которой смесь золы и сажи (аморфного углерода) выдерживалась от 0.5 до $3 \mathrm{~h} \mathrm{в}$ атмосфере азота при температуре $1500^{\circ} \mathrm{C}$. Соответственно полученные экспериментальные данные не противоречат известным сведениям о процессах переработки золы с получением в качестве продуктов карбидов кремния и нитрида алюминия. На дифрактограмме очищенного от углерода в атмосферной печи и затем спеченного методом SPS материала (рис. 1, кривая 3) однозначно идентифицируется основная фаза кубического $\mathrm{SiC}$, видны следы гексагональной фазы $\mathrm{SiC}$, гексагонального AlN, малоинтенсивные следы нескольких фаз, которые могут соответствовать карбидам и оксидам различных металлов и неметаллов, находящихся в составе золы. Кроме того, идентифицируется единичный малоинтенсивный максимум в районе $\sim 26 \mathrm{deg}$, который 
$a$

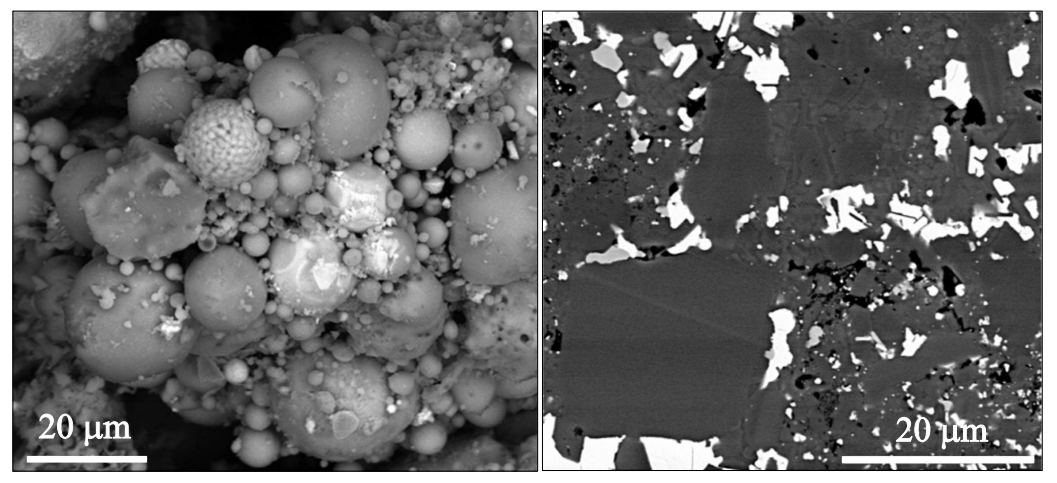

$b$

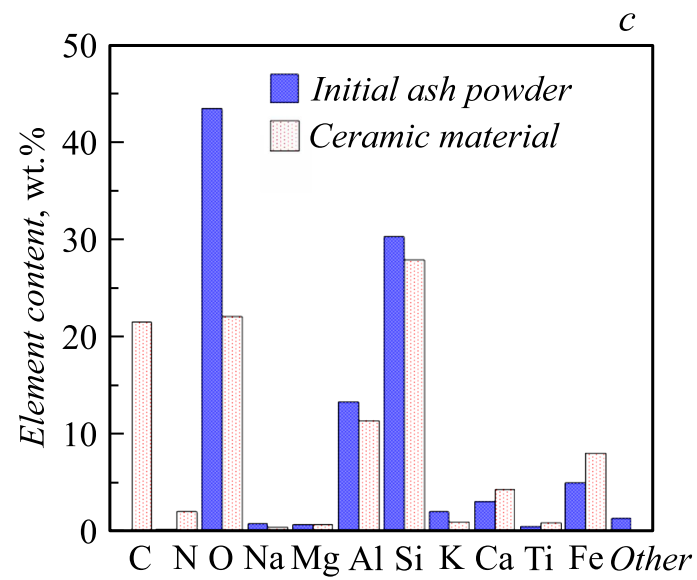

Рис. 2. Результаты растровой электронной микроскопии и энергодисперсионного анализа. $a-$ снимок исходного золошлакового материала, $b$ - снимок спеченного керамического материала, $c$ - энергодисперсионные спектры исходного золошлакового материала и спеченного керамического материала.

может соответствовать небольшому содержанию графита и/или корунда, являющихся, вероятно, остатками непрореагировавшего материала, а также эродированного графита или графита от пуансонов и матрицы графитовой пресс-формы для спекания.

По данным растровой электронной микроскопии исходный материал (зола) преимущественно состоит из сферических объектов с размерами от $\sim 1$ до $\sim 25 \mu \mathrm{m}$ (рис. 2,a). Такая морфология частиц и диапазон их размеров соответствуют известным представлениям о морфологии частиц золошлаковых материалов [2,14]. Согласно типичным энергодисперсионным спектрам (рис. 2,c, закрашенные столбики), в составе исходной золы доминируют $\mathrm{O}, \mathrm{Al}, \mathrm{Si}, \mathrm{Fe}$, а также присутствуют в количестве долей и единиц массовых процентов $\mathrm{Na}$, $\mathrm{Mg}, \mathrm{K}, \mathrm{Ca}, \mathrm{Ti}$ и некоторые другие элементы со значительно меньшим содержанием. На шлифе спеченного керамического образца (рис. $2, b$ ) видно, что морфология частиц в сравнении с исходной изменилась. На поверхности шлифа просматриваются единичные кристаллиты с размерами до 20-30 $\mu$ m и признаками правильной естественной огранки, образования неправильной формы, характеризующиеся большей плотностью (видимо, содержащие металлы) с размерами до 5-10 $\mu \mathrm{m}$. Также на снимке просматриваются поры с размерами до нескольких микрометров. Согласно данным энергодисперсионного анализа (рис. 2, $c$, светлые столбики), химический состав типичного керамического образца существенно изменился в сравнении с исходной золой: до 20-22 wt.\% образца составляет C; практически вдвое (до 20-23 wt.\%) снижается содержание О; в заметных количествах (интегрально до 2-3 wt.\%, локально до 10-15 wt.\%) идентифицируется N. Эти результаты подтверждают данные рентгеновской дифрактометрии: основными фазами в составе продукта могут быть $\mathrm{SiC}$ и $\mathrm{AlN}$, при этом образцы также могут содержать оксиды металлов и неметаллов, являющиеся непереработанными в плазме остатками компонентов золы или же образовавшимися в процессе отжига образцов при их очистке от несвязанного углерода оксидными фазами.

Анализ микротвердости шлифа синтезированного керамического образца показал, что наибольшая величина твердости в серии измерений составила $19.9 \mathrm{GPa}$ при средней в серии измерений величине $15.8 \mathrm{GPa}$. Такие величины твердости соответствуют керамическим образцам на основе $\mathrm{SiC}$ и $\mathrm{AlN}$, полученным другими методами [15]; соответственно получаемый материал сравним по твердости с аналогами близкого состава.

В результате проведенных экспериментальных исследований показана возможность переработки порошковых золошлаковых отходов в плазме дугового разряда постоянного тока безвакуумным методом. В реализованном процессе оксидные фазы на основе кремния и алюминия, составляющие основную массу золошлаковых отходов, трансформируются в карбидные и нитридные. Полученный материал после предварительной очистки пригоден для консолидации методом SPS. Получаемый в итоге объемный керамический материал характеризуется твердостью до $19.9 \mathrm{GPa}$.

\section{Благодарности}

Работа выполнена с использованием оборудования Наноцентра Томского политехнического университета, а также Томского материаловедческого центра коллективного пользования, входящего в состав Томского регионального центра коллективного пользования Томского государственного университета.

\section{Финансирование работы}

Работа выполнена в ходе реализации проекта FSWW-2020-0022 государственного задания „Наука“ (эксперименты по переработке золошлаковых отходов), 
а также в рамках программы повышения конкурентоспособности Томского политехнического университета, проект ВИУ-НРиИ-346/2019 (анализ синтезированных материалов).

\section{Конфликт интересов}

Авторы заявляют, что у них нет конфликта интересов.

\section{Список литературы}

[1] Cruz N.C., Silva F.C., Tarelho L.A.C., Rodrigues S.M. // Resour. Conserv. Recycl. 2019. V. 150. P. 104427. https://doi.org/10.1016/j.resconrec.2019.104427

[2] Gollakota A.R.K., Volli V., Shu C.-M. // Sci. Total Environ. 2019. V. 672. P. 951-989. https://doi.org/10.1016/j.scitotenv.2019.03.337

[3] Li J., Liu K., Yan S.J., Li Y.J., Han D. // Waste Management. 2016. V. 58. P. 260-269. http://dx.doi.org/10.1016/j.wasman.2016.06.011

[4] Gomez E., Rani D.A., Cheeseman C.R., Deegan D., Wise M., Boccaccini A.R. // J. Hazard. Mater. 2009. V. 161. P. 614-626. DOI: 10.1016/j.jhazmat.2008.04.017

[5] Deng J., You Y., Sahajwalla V., Joshi R.K. // Carbon. 2016. V. 9. P. 105-115. http://dx.doi.org/10.1016/j.carbon.2015.09.033

[6] Ho G.S., Faizal H.M., Ani F.N. // Waste Management. 2017. V. 69. P. 423-430. http://dx.doi.org/10.1016/j.wasman.2017.08.015

[7] Li C., Zhou Y., Tian Y., Zhao Y., Wang K., Li G., Chai Y. // Ceram. Int. 2019. V. 45. P. 5613-5616. https://doi.org/10.1016/j.ceramint.2018.12.021

[8] Ma B., Su C., Ren X., Gao Z., Qian F., Yang W., Liu G., Li H., Yu J., Zhu Q. // J. Alloys Compd. 2019. V. 803. P. 981-991. https://doi.org/10.1016/j.jallcom.2019.06.272

[9] Пак А.Я. // Письма в ЖТФ. 2019. Т. 45. В. 17. С. 16-19. DOI: 10.21883/PJTF.2019.17.48217.17877

[10] Joseph Berkmans A., Jagannatham M., Rohit Reddy D., Haridoss P. // Diamond Relat. Mater. 2015. V. 55. P. 12-15. http://doi.org/10.1016/j.diamond.2015.02.004

[11] Arora N., Sharma N.N. // Diamond Relat. Mater. 2014. V. 50. P. 135-150. https://doi.org/10.1016/j.diamond.2014.10.001

[12] Wang $Q ., W u W$., Zhang J., Cong R. // Mater. Sci. Eng. B. 2018. V. 238-239. P. 108-114. https://doi.org/10.1016/j.mseb.2018.12.020

[13] Hongjie $W$., Yonglan W., Zhihao J. // J. Mater. Process. Technol. 2001. V. 117. P. 52-55.

[14] Yang T., Zhu H., Zhang Z., Gao X., Zhang C., Wu Q. // Cement Concrete Res. 2018. V. 109. P. 198-207. https://doi.org/10.1016/j.cemconres.2018.04.008

[15] Lim C.S., Kim J.C., Auh K.H. // Mater. Lett. 2000. V. 45. P. 101-106. 